\section{Conversion to Mechanical Pruning in Vineyards Maintains Fruit Composition while Reducing Labor Costs in 'Merlot' Grape Production}

\author{
S. Kaan Kurtural ${ }^{1,7}$, Andrew E. Beebe ${ }^{1,2}$, \\ Johann Martínez-Lüscher ${ }^{1}$, Shijian Zhuang ${ }^{3}$, \\ Karl T. Lund ${ }^{4}$, Glenn McGourty ${ }^{5}$, and Larry J. Bettiga ${ }^{6}$
}

ADDITIONAL INDEX WORDS. anthocyanin, mechanical pruning, hot climate viticulture, trellis

Summary. A field study was conducted for three consecutive seasons in the hot climate of central California to assess the performance of 'Merlot' grapevine (Vitis vinifera) grafted onto 'Freedom' [Fresno 1613-59 $\times$ Dog Ridge 5 (27\% V. vinifera hybrid)] during training system conversion to facilitate mechanization. The traditional head-trained and cane-pruned (CP) system was either retained or converted either to a bilateral cordon-trained, spur-pruned California sprawl training system (HP), or to a bilateral cordon-trained, mechanically box-pruned single high-wire sprawling system (SHMP). After the conversion, SHMP sustained greater yield with more clusters per vine and smaller berries without affecting the canopy microclimate. This was due to a higher number of nodes retained after dormant pruning. The SHMP canopies, compared with CP and HP; filled allotted canopy space earlier based on photosynthetically active radiation $(P A R)$ transmitted through the canopies, populating the space allotted per vine, favoring higher production efficiency. There were no adverse effects of training systems on berry composition or flavonoid concentration, during or after conversion to mechanical management. However, experimental year effect was obvious on anthocyanin composition of 'Merlot' berries, increasing trihydroxylated (i.e., delphinidinbased) anthocyanins in the latter years of the experiment. Our results also provided evidence that earlier canopy growth coupled with sufficient reproductive compensating responses allowed for increased yields while reaching commercial maturity without a decline in anthocyanin content with the SHMP. Converting CP to SHMP reduced labor operations costs by $\mathbf{9 0 \%}$. Furthermore, the SHMP had greater gross revenue and resulted in greater net income per acre even when the conversion year was taken into account. Therefore, SHMP is recommended for growers within the hot climate of the central San Joaquin Valley as a means to maintain productivity of vineyards while not sacrificing berry composition at the farm gate.

$\mathrm{T}$ The wine grapes grown in the San Joaquin Valley (SJV) are the staple of California's wine industry. More than $50 \%$ of California grapes crushed for wine are grown in the SJV [California Department of Food and Agriculture (CDFA), 2013]. However, the rising cost of labor presents an economic risk for SJV vineyards (Kurtural et al., 2012). The average net return for wine grapes in central SJV is $\$ 327 /$ ton (CDFA, 2013). The low net returns, coupled with rising labor costs and seasonal droughts, have decreased sustainability of production of wine grapes in the region. Therefore, grape growers are in need of methods to reduce labor costs.

Traditional vineyards in the study area are head-trained to a 38-inch-tall trunk above the vineyard floor with two, eight-node canes laid on to a catch wire in opposing directions. An additional two, eightnode canes are also attached onto a catch wire 66 inches above the vineyard floor. Although this traditional training system facilitated production goals, such as mechanical harvesting, it was proven difficult to facilitate mechanical management, such as dormant pruning (Kurtural et al., 2012) and shoot removal (Terry and Kurtural, 2011), with some success in mechanical leaf removal (Cook et al., 2015; Yu et al., 2016). Previously, we investigated mechanizing dormant and growing season cultural practices on grapevine trained to common trellis systems used in California (Brillante et al.,
2018; Kurtural et al., 2012, 2013; Terry and Kurtural, 2011; Wessner and Kurtural, 2013) in vineyards trellised specifically for experimental purposes. However, there is a lack of information on how grapevines respond to conversion from headtrained and $\mathrm{CP}$ vineyards to mechanical management. Furthermore, it is not economically feasible to replant unless absolutely necessary, as the cost for reestablishing a vineyard in the region is $\$ 15,600$ per acre (Verdagaal et al., 2016).

Mechanical canopy management is performed across a number of climates and has made advances in vineyard management that have increased production efficiency along with the ability to improve yield and berry composition. Recent vineyard mechanization research performed in California in a climate corresponding to Region $\mathrm{V}$ of the Winkler scale [ $>2222$ growing degree days (GDD) $10{ }^{\circ} \mathrm{C}$ base (Amerine and Winkler, 1944)] suggested that adjusting shoot density mechanically was desirable to produce sustainable yields, improve canopy microclimate, and achieve recommended fruit weightto-pruning ratios (Kurtural et al., 2013; Wessner and Kurtural, 2013). However, decreasing shoot densities in hot climates such as Region $\mathrm{V}$ either mechanically or manually provided no further benefit to canopy function. The lack of response from increased severity of shoot thinning was likely due to lateral bud growth, which negated part of the effect of the canopy management practices (Geller and Kurtural, 2013; Kurtural et al., 2013). Furthermore, our recent work corroborated this finding where a single high-wire training system outperformed a split canopy trellis, and the traditional California sprawl (Martínez-Lüscher et al., 2017a). This work concluded that increased irrigation amounts and bigger canopies contributed to sustaining higher yields and berry flavonoid content for mechanically pruned grapevines compared with hand-pruned grapevines when canopy size was managed with the application of $80 \%$ crop evapotranspiration irrigation replacement. Therefore, instead of implementing mechanical canopy management practices, many growers are attempting to convert existing vineyards to a single high-wire sprawling system and 
managing the spur height with mechanical box pruning. The objective of this study was to investigate the effects of training systems on components of yield, and berry chemistry of 'Merlot' grapevine during and after conversion to mechanical management in a hot climate viticulture region.

\section{Materials and methods}

EXPERIMENTAL SITE AND PLANT MATERIAL. This study was conducted from 2013 to 2015 at a commercial vineyard planted with 'Merlot' (clone FPS03) grafted onto 'Freedom' rootstock at a $7 \times 11-\mathrm{ft}($ vine $\times$ row $)$ spacing in north-south orientation. The research site was located in Madera, CA, and was planted in 1995 on Atwater loamy sand (coarse-loamy, mixed, thermic Typic Haploxeralf) and Cometa sandy loam (fine, mixed, superactive, thermic Typic Palexeralf) (U.S. Department of Agriculture, 2006). The vines were trained to 38-inch-tall trunks, with two, eightnode canes trained at 44 inches and an additional two, 14-node canes that were trained at 54 inches, in opposing directions. The vineyard was dripirrigated according to the grower's schedule with pressure compensating emitters spaced at 36 inches with two emitters per vine delivering $0.5 \mathrm{gal} / \mathrm{h}$. The vineyard received $1.67,1.62$, and 1.59 acre-ft of irrigation water in 2013, 2014 , and 2015, respectively. All other cultural practices were standard for the

Received for publication 4 Oct. 2018. Accepted for publication 8 Jan. 2019.

Published online 26 February 2019.

The authors acknowledge the American Vineyard Foundation for partial funding during the execution of this study.

${ }^{1}$ Department of Viticulture and Enology, University of California Davis, 1 Shields Avenue, Davis, CA 95616

${ }^{2}$ Junior Specialist. Current address: Roederer Estates Winery, 4501 CA-128, Philo, CA 95466

${ }^{3}$ University of California Cooperative Extension, 550 E. Shaw Avenue, Fresno, CA 93704

${ }^{4}$ University of California Cooperative Extension, 328 S. Madera Avenue, Madera, CA 93637

${ }^{5}$ University of California Cooperative Extension, 890 N. Bush Street, Ukiah, CA 95482

${ }^{6}$ University of California Cooperative Extension, 1432 Abbot Street, Salinas, CA 93901

${ }^{7}$ Corresponding author. E-mail: skkurtural@ucdavis. edu.

This is an open access article distributed under the CC BY-NC-ND license (https://creativecommons.org/ licenses/by-nc-nd/4.0/).

https://doi.org/10.21273/HORTTECH04204-18 area and conducted according to the University of California Cooperative Extension guidelines (University of California, 2014).

The experiment compared three training systems in a randomized complete block design and four replicated blocks in a 53 -acre vineyard. Within the confines of the experiment, each replication contained 376 vines per plot, of which 24 were sampled (96 total samples). The same plants were used for all treatments in all years of the study.

Training SYSTEM TREATMENTS. Three training system treatments were applied: The CP treatment consisted of plants trained to a 38 -inchtall trunk above the vineyard floor with four, eight-node canes retained in opposing directions at 38 and 54 inches high. Maintaining this system served as the control. The other two training systems were converted as follows. The trellis was converted to a hand-pruned California sprawl system (HP) with a cordon wire at 54 inches above the vineyard floor and two parallel catch wires, with a 10inch cross-arm at 66 inches above the vineyard floor and spur pruned to retain 22 spurs with two nodes each per vine. During the conversion year (2013), two canes $\approx 54$ inches long were retained. These canes were tied to the line stake, and laid onto the cordon wire at 54 inches above the vineyard floor, in a north-south direction in 18-inch segments. When shoots from apical buds reached $\approx 22$ inches in length, they were also laid down on the cordon wire to fill the allotted space. The fruit from the canes used in retraining were not removed during the conversion year 3 . The trellis was also converted to a single high-wire mechanically pruned. The cordon wire was established 66 inches above the vineyard floor and a bilateral cordon was established to establish a single high-wire system that was mechanically boxpruned with a 2 -ft-wide mechanical pruner (Mechanical Sprawl Pruner; V-Mech, Fresno, CA) at a 4.2 -inch spur height. The SHMP was converted in the following manner. Two canes $\approx 58$ inches long were retained during the conversion year (2013). They were tied to the line stake, and laid onto the cordon wire in 22 -inch segments in a north-south direction, at 66 inches above the vineyard floor. After the apical bud burst and the resulting shoot reached $\approx 18$ inches in length, it was laid down on the cordon to fill the allotted space. The fruit from the canes used in retraining were not removed during conversion to SHMP.

CANOpy architecture AND LEAF AREA. Canopy architecture measurements, such as leaf layers, cluster contacts, and canopy gap percentage were measured as described by Smart and Robinson (1991). PAR was measured as follows. A ceptometer (AccuPAR-80; Meter Group, Pullman, WA) was placed directly above the cordon, within the fruiting zone on the east side of the canopies parallel to the vine row at the head of each vine. Four measurements were taken with the ceptometer from four vines within each experimental unit. Ambient PAR measurements were taken at a height of 4 inches above the canopy surface. The remaining three measurements were taken within the fruiting zone at the head of the vine.

\begin{tabular}{llll}
\hline $\begin{array}{l}\text { Units } \\
\text { To convert U.S. to SI, } \\
\text { multiply by }\end{array}$ & U.S. unit & SI unit & $\begin{array}{l}\text { To convert SI to U.S., } \\
\text { multiply by }\end{array}$ \\
\hline 0.4047 & $\mathrm{acre}(\mathrm{s})$ & $\mathrm{ha}$ & 2.4711 \\
1233.4819 & $\mathrm{acre}-\mathrm{ft}$ & $\mathrm{m}^{3}$ & 0.0008 \\
29.5735 & $\mathrm{fl} \mathrm{oz}$ & $\mathrm{mL}$ & 0.0338 \\
0.3048 & $\mathrm{ft}$ & $\mathrm{m}$ & 3.2808 \\
0.0929 & $\mathrm{ft}^{2}$ & $\mathrm{~m}^{2}$ & 10.7639 \\
0.2048 & $\mathrm{ft}^{2} / \mathrm{lb}$ & $\mathrm{m}^{2} \cdot \mathrm{kg}^{-1}$ & 4.8824 \\
3.7854 & $\mathrm{gal}$ & $\mathrm{L}$ & 0.2642 \\
2.54 & inch(es) & $\mathrm{cm}$ & 0.3937 \\
25.4 & inch $(\mathrm{es})$ & $\mathrm{mm}$ & 0.0394 \\
0.4536 & $\mathrm{lb}$ & $\mathrm{kg}$ & 2.2046 \\
1.6093 & $\mathrm{mph}$ & $\mathrm{km} \cdot \mathrm{h}^{-1}$ & 0.6214 \\
28.3495 & $\mathrm{oz}$ & $\mathrm{g}$ & 0.0353 \\
28,350 & $\mathrm{oz}$ & $\mathrm{mg}$ & $3.5274 \times 10^{-5}$ \\
0.001 & $\mathrm{ppm}$ & $\mathrm{g} \cdot \mathrm{L}^{-1}$ & 1000 \\
1 & $\mathrm{ppm}$ & $\mathrm{mg} \cdot \mathrm{kg}^{-1}$ & 1 \\
0.9072 & ton $(\mathrm{s})$ & $\mathrm{Mg}$ & 1.1023 \\
$\left({ }^{\circ} \mathrm{F}-32\right) \div 1.8$ & ${ }^{\circ} \mathrm{F}$ & ${ }^{\circ} \mathrm{C}$ & $\left({ }^{\circ} \mathrm{C} \times 1.8\right)+32$ \\
& & &
\end{tabular}


Measurements were taken at canopy closure (when shadow on vineyard berm no longer changes (Terry and Kurtural, 2011), and at veraison at solar noon with $P A R$ values ranging $\approx 1900$ to $2200 \mu \mathrm{mol} \cdot \mathrm{m}^{-2} \cdot \mathrm{s}^{-1}$. The three fruiting zone $P A R$ measurements were combined and expressed as the percentage of total $P A R$ measured at midday. Leaf area was determined as follows. Two shoots per vine were randomly selected and stored at $37{ }^{\circ} \mathrm{F}$ at $98 \%$ humidity in cold storage until measured. Each shoot was separated into main and lateral axes. The number of leaves per axes was counted, and leaf area was measured with a leaf area meter (LI-3000; LI-COR, Lincoln, $\mathrm{NE}$ ). The canopy leaf area per vine was then determined as described by Keller et al. (2008)

YIELD COMPONENTS AND BERRY composition. Fruit yield and cluster numbers for each treatment were measured by hand, harvesting 24 vines from each experimental unit when the fruit reached total soluble solids (TSS) of $23 \%$. Average cluster weight was calculated by dividing fruit yield per vine by the number of clusters harvested per vine. Leaf areato-fruit ratio was calculated by dividing the leaf area at full-veraison of each vine by the yield per vine and was expressed as square meters per kilogram. Berry composition was determined at harvest. A random 100-berry sample was collected from 24 vines from each experimental unit, placed into polyethylene bags, stored on ice, and analyzed within $24 \mathrm{~h}$. Before analysis, the 100-berry samples were weighed, and average berry weight was determined. The samples were then crushed by hand and the juice placed in $50-\mathrm{mL}$ beakers. A 5-mL sample was used to determine the TSS using a digital refractometer (PAL-1; Atago, Tokyo, Japan). Juice $\mathrm{pH}$ was determined using a glass electrode and a $\mathrm{pH}$ meter (model XLl5; Fisher Scientific, Pittsburgh, PA). Titratable acidity (TA) of each sample was determined by titrating to a $\mathrm{pH}$ of 8.2 with $0.1 \mathrm{~N}$ sodium hydroxide using an endpoint titrator (model DL 15; Mettler-Toledo, Columbus, $\mathrm{OH})$, and expressed as grams per liter of tartaric acid.

BERRY FLAVONOID COMPOSITION. Flavonoid composition of the berry was determined on a separate set of 20-berry samples following the procedure as developed by Cook et al. (2015) and $\mathrm{Yu}$ et al. (2016) using reversed-phase high-performance liquid chromatography (HPLC). At harvest, 20 -berry samples were collected, weighed, and stored at $-80{ }^{\circ} \mathrm{C}$ until analyzed. Berry skins were separated from the pulp and lypholized (Triad Freeze Dry System; Labconco, Kansas City, MO). The compounds from skins were then extracted in $20 \mathrm{~mL}$ $2: 1$ acetone:water $(\mathrm{v} / \mathrm{v})$ in darkness for $24 \mathrm{~h}$. Extracts were filtered and placed into a centrivap (model 7810010; Labconco) connected to a cold trap (model 7385020; Labconco) to evaporate the acetone phase. Aqueous extracts were then precipitated and brought up to a volume of $5 \mathrm{~mL}$. After centrifugation for $15 \mathrm{~min}$ at $1400 g_{\mathrm{n}}$, supernatants were transferred into another tube for HPLC analyses. Briefly, an HPLC system (model 1100; Agilent Technologies, Santa Clara, CA) was used, coupled to a diode array detector. A reverse-phase column $(5 \mu \mathrm{m}$ packing, $250 \times 4 \mathrm{~mm}$, LiChrospher $100 \mathrm{RP}$ 18; Agilent Technologies) was used, protected with a guard column of the same material and thermostatted at $40{ }^{\circ} \mathrm{C}$. Tannins in grape skins were measured spectrophotometrically (Lambda 25 ultraviolet/VIS; PerkinElmer, Waltham, MA) based on a procedure described by Kurtural et al. (2012). Briefly, an aliquot of aqueous extract was added to a solution of bovine serum albumin (SigmaAldrich, St. Louis, MO), isolating the tannin-protein complex, dissolving it in alkaline solution and adding ferric chloride. Concentrations were determined using a standard curve for catechin (catechin hydrate; SigmaAldrich).

Cost calculations. All labor, benefit, and fuel rates used in cost calculations were obtained from Verdagaal et al. (2016). The average grower returns per ton of grapes delivered for 'Merlot' were obtained from the California Grape Crush Reports for each year (CDFA, 2013, $2014,2015)$. The time to apply the $\mathrm{CP}$ and HP treatments and the follow-up labor were measured by timing the same trained laborer in each treatment replicate every year. The time to accomplish these tasks was then divided by the number of vines in the replicates measured, then the labor hours and cost per acre were calculated by multiplying the time and cost per vine by the number of vines per acre. Cost calculations in the SHMP treatment were done as follows. The time to accomplish the mechanical pruning and equipment maintenance were measured by timing the same trained operator in 2014 and 2015 in each treatment replicate. A cost per vine to accomplish each task was calculated, multiplied by the appropriate labor and benefit rate and labor cost per acre was calculated by multiplying the resultant costs by the number of vines per acre. The number of hours the mechanical pruner operated was multiplied by the fuel cost to calculate the fuel cost. The labor and fuel costs were added to calculate the cost per acre.

Statistical analysis. Data for all measured parameters were tested to verify if the assumptions of analysis of variance (ANOVA) were met. Normality was tested using ShapiroWilk's test and data that failed to meet the assumptions of ANOVA were $\log 10$ transformed and analyzed using the generalized linear model procedure in SAS (version 9.3; SAS Institute, Cary, NC). Significance level was set at $P \leq 0.05$ and means were separated using Tukey's honestly significant difference test. When the ANOVA showed significant differences, the mean separation test was conducted on the transformed data, but the nontransformed means were presented for ease of discussion. Interactions between year and treatments were tested and whenever these interactions were significant $(P<0.05)$ analysis was conducted separately for each year.

\section{Results and discussion}

WEATHER AT THE EXPERIMENTAL SITE. During this experiment, California was in a period of extended drought where average temperatures have increased and average rainfall decreased. In 2014, the first year of the study after the training system conversion, the vineyard received only $51 \%$ of the 10 -year precipitation average, and the second year received $38 \%$ (Fig. 1). Furthermore, most of the precipitation received was concentrated during the winter period and early in the growing season. It was clear that rainfall in the study area 
was very low with only 91 and $115 \mathrm{~mm}$ of precipitation in 2014 and 2015, respectively. Less than half of the precipitation fell during the winter period for both years. Mendez-Costabel et al. (2014) concluded that the exclusion of winter precipitation reduced canopy development, regardless of applied water amounts during the growing season. The minimal rainfall seen during winter in this study exacerbated the issue of canopies filling their allotted space by bunch closure; however, similar canopy architecture values were measured in the years after the conversion. Harvest commenced during early and mid-August throughout the 3 years of study, which indicated the precocity of grapevine phenology under such hot climate (Table 1 ). In addition, projected scenarios of global warming may have an uncertain outcome for regions at the edge of sustainability (Webb et al., 2013).

EFFECT OF TRAINING Systems ON CANOPY ARCHITECTURE. Achieving balanced canopies in hot climates like the SJV can be difficult, as grapevine canopies under such conditions tend to have a precocious and rapid development, particularly when irrigation and nutrients are not restricted, leading to dense and shaded canopies (Kurtural et al., 2013). Canopy architecture was measured at two phenological periods: preveraison (PV) and preharvest $(\mathrm{PH})$. There was an effect of experimental year on leaf layer numbers, cluster contacts, and

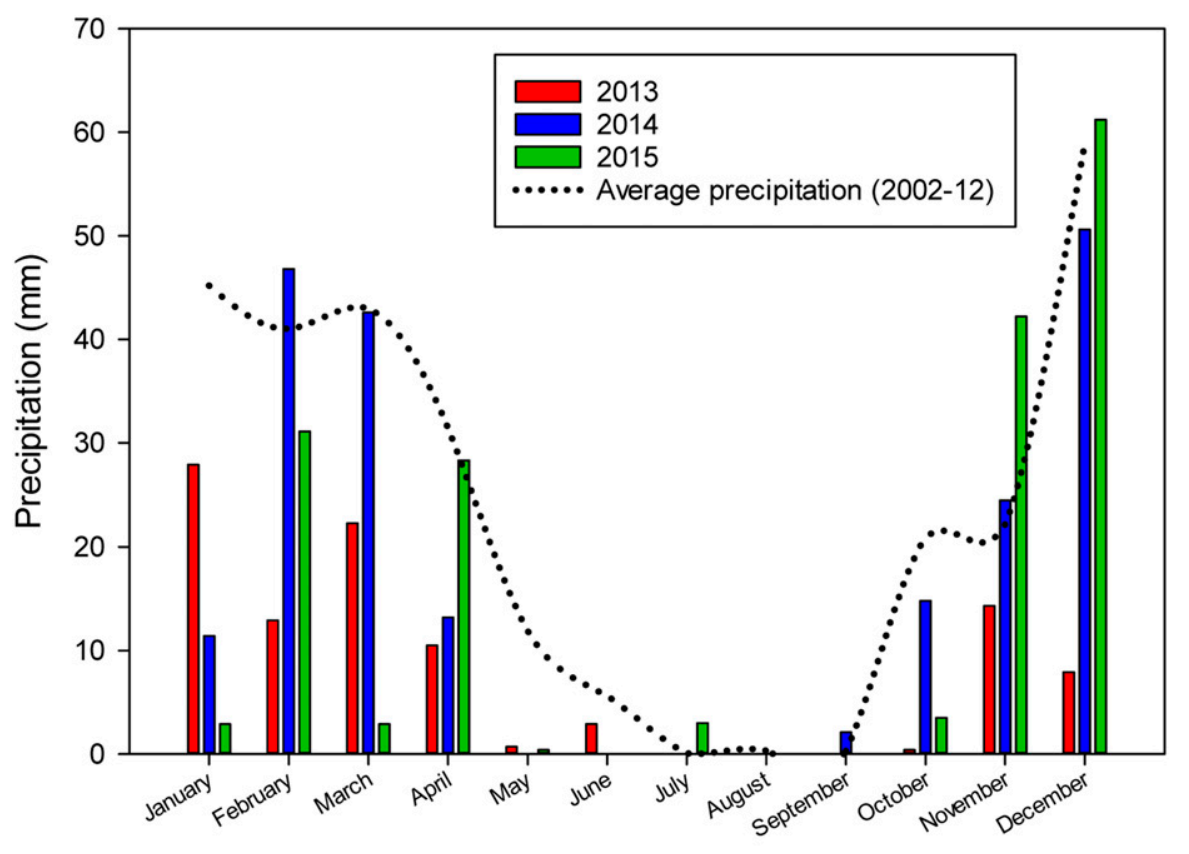

Months of year

Fig. 1. Average monthly precipitation 2002-12 and precipitation received during the experimental period (2013-15) by months at the 'Merlot' grapevine on 'Freedom' rootstock vineyard; $1 \mathrm{~mm}=0.0394$ inch.

percent canopy gaps for both the PV and $\mathrm{PH}$ periods (Table 2 ). However, year affected $P A R$ transmittance only during the PV. This precocious and rapid canopy development was observed regardless of whether dormant season pruning was applied mechanically or by hand (Wessner and Kurtural, 2013). However, during extended droughts, such as that experienced during this experiment, grapevine canopy development can be restricted despite irrigation. The restriction of canopy development can be exacerbated further when winter precipitation is minimal (MendezCostabel et al., 2014), as during this experiment, which led to an effect of year in which canopy density parameters decreased in 2014 and 2015. In 2014 , there was an interaction between year and training systems in which the CP treatment had the lowest leaf layer number during the PV period. In 2014 and 2015, the SHMP treatment had the greatest number of cluster contacts during the PH period. The SHMP treatment retained a higher cluster contact value only during the PV period in 2015. In 2014 , the CP treatment had the greatest canopy gap percentage value during the PV period. However, the same result was not evident in the $\mathrm{PH}$ period or either of the periods in 2015 . Leaf area was consistently greater in the SHMP treatment for both years and both the PV and PH periods. The SHMP treatment increased total vine leaf area by $28 \%$ and $33 \%$ compared with CP in 2014 and 2015 during the PV period, respectively. The SHMP treatment increased total vine leaf area by $26 \%$ and $22 \%$ over that of CP in 2014 and 2015 during the $\mathrm{PH}$ period, respectively.

The trellis conversion from conventional systems to a mechanically pruned system performed in 2013

Table 1. Dates for 'Merlot' grapevines on 'Freedom' rootstock for key phenological and management stages in a study from 2013 to 2015 in the central San Joaquin Valley of California.

\begin{tabular}{|c|c|c|c|c|c|c|c|}
\hline Phenological stage & $\begin{array}{l}\text { Modified } \\
\text { E-L stage }\end{array}$ & $\begin{array}{c}\text { Date } \\
(2013)\end{array}$ & $\begin{array}{l}\text { GDD } \\
(2013)^{y}\end{array}$ & $\begin{array}{c}\text { Date } \\
(2014)\end{array}$ & $\begin{array}{l}\text { GDD }^{y} \\
(2014)\end{array}$ & $\begin{array}{c}\text { Date } \\
(2015)\end{array}$ & $\begin{array}{c}\text { GDD } \\
(2015)\end{array}$ \\
\hline Bud break & 4 & 19 Mar. & 29 & 20 Mar. & 24 & 17 Mar. & 25 \\
\hline Fruit set & 27 & 5 June & 732 & 9 June & 583 & l June & 595 \\
\hline Veraison & 35 & 14 July & 1,340 & 14 July & 1,070 & 11 July & 1,193 \\
\hline Harvest & 38 & 12 Aug. & 1,790 & 6 Aug. & 1,624 & 17 Aug. & 1,813 \\
\hline
\end{tabular}

${ }^{\mathrm{z}}$ Modified Eichhorn-Lorenz system for identifying major and intermediate grapevine growth stages (Coombe, 1995).

${ }^{\mathrm{y}}$ Growing degree days $(\mathrm{GDD})$ in with base temperature at $10^{\circ} \mathrm{C}\left(50.0^{\circ} \mathrm{F}\right) ; 1 \mathrm{GDD}$ with base temperature $\left(\mathrm{T}_{\text {base }}\right)=10{ }^{\circ} \mathrm{C}$ corresponds to $1.9 \mathrm{GDD}$ with $\mathrm{T}_{\text {base }}=50^{\circ} \mathrm{F}$. 
Table 2. Effect of training systems on canopy architecture and microclimate of 'Merlot' grapevines on 'Freedom' rootstock in central San Joaquin Valley of California $(n=4)$.

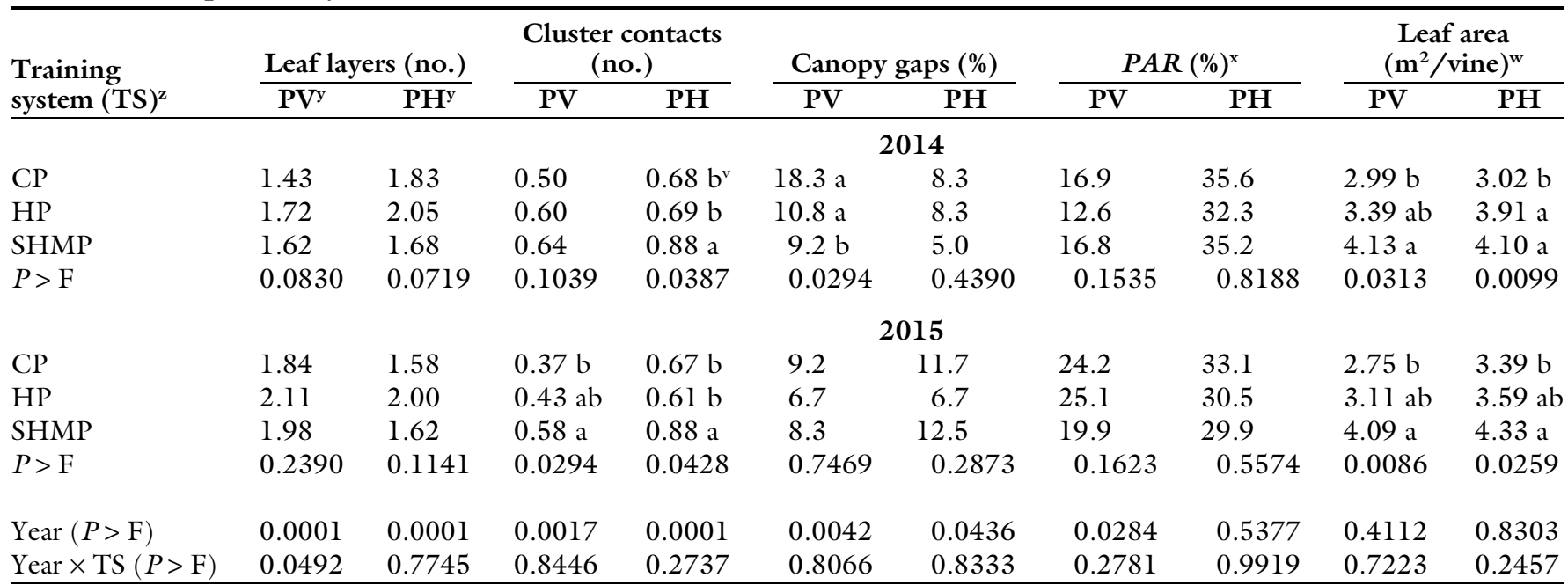

${ }^{\mathrm{z}} \mathrm{CP}=$ trained to a 38 -inch-tall trunk, with four eight-node canes trained at 44 inches and an additional two eight-node canes that were trained at 54 inches, in opposing directions; $\mathrm{HP}=$ California sprawl system with a cordon wire at 54 inches above vineyard floor and two parallel catch wires at 66 inches above the vineyard floor and spur pruned to retain 22 spurs with two nodes each per vine; SHMP = single high-wire sprawling system cordon wire was established 66 inches above the vineyard floor and a bilateral cordon was established to generate a single high-wire system that was mechanically box-pruned at a 4.2 -inch spur height; 1 inch $=2.54 \mathrm{~cm}$.

${ }^{\mathrm{y}} \mathrm{PV}=$ preveraison; $\mathrm{PH}=$ preharvest.

${ }^{x}$ Photosynthetically active radiation percentage reaching the fruit zone.

${ }^{\mathrm{w}} 1 \mathrm{~m}^{2}=10.7639 \mathrm{ft}^{2}$

${ }^{v}$ Columns with no letters in common indicate statistical separation at $P<0.05$ according to Tukey's honestly significant difference.

created distinct PV canopy architectures (Table 2). The cluster contacts for this experiment were the most affected architecture variable where pruning system was the primary contributor. Cluster contacts were consistently greater in the SHMP system, indicating a higher cluster density within this canopy configuration. These results are in agreement with other mechanical management trials where reducing the severity of pruning level by the application of mechanical winter pruning had the tendency to retain a higher number of nodes, therefore leading to more shoots and clusters per vine (Geller and Kurtural, 2013; Kurtural et al., 2013). More strikingly, the leaf layers measured in this study were found to range from 1.5 to 2 which were well below those of reported values for the area in our previous work (Terry and Kurtural, 2011), in which we considered that between three to four leaf layers may offer better protection to the fruit from sunburn. These low values may indicate a greater amount of fruit exposure to direct sunlight, which was shown to adversely affect berry flavonoid content (Bergqvist et al., 2001; Martínez-Lüscher et al., 2017a), particularly in hot climates such as the SJV.

There were few discernable differences seen between canopy architecture variables among treatments postveraison. This indicated that canopies were fully developed relatively early in the season rather than continuing to develop, as would be expected in cooler climates (Howell, 2001). This may have played a role in restricting SHMP leaf area, one of the major advantages of mechanically managed systems. The data presented indicated an earlier development of total leaf area per vine by the SHMP system, where it produced 19\% more leaf area than what was produced by the traditional systems (CP and HP) at PV. There is agreement in the literature that viticulturalvsystems that maintain higher amounts of buds, such as mechanically pruned systems, initiate and maintain larger leaf areas when compared with traditional pruning methods (De Toda and Sancha, 1999; Wessner and Kurtural, 2013). The greater capacity of the SHMP system to increase yields was attributed to a higher number of buds, and therefore more clusters, but also to a larger leaf area, contributing to the ripening of these high yields. The $\mathrm{CP}$ treatment reduced the total leaf area compared with the other treatments. It was reported that $\mathrm{CP}$ vines when supplied with sufficient irrigation to meet vine water demands can produce greater active canopies that may support greater yields (Wessner and Kurtural, 2013). However, when water availability appeared to be limiting, CP tended to underperform in production in hot climates (Martínez-Lüscher et al., 2017a).

EFFECT OF TRAINING SYSTEMS ON YIELD COMPONENTS. Year affected berry weight, clusters per vine, cluster weight, yield, and berry skin weight (Table 3). Berry weight, clusters per vine, cluster weight, and yield decreased in subsequent years whereas skin weight increased. The SHMP treatments displayed the least decrease in yield per year followed by the HP and CP treatments in concert with our previous work (MartínezLüscher et al., 2017a). Training systems affected berry weights in all years. The CP treatment had lower berry weights during the 2013 conversion year compared with 2014 and 2015. The SHMP treatment reduced berry weights by $7 \%$ and $5 \%$ compared with other pruning systems in 2014 and 2015 , respectively, as we previously reported (Geller and Kurtural, 2013; Terry and Kurtural, 2011). Cluster numbers per vine were affected by training systems in all years. The HP treatment had greater cluster numbers in 2013 compared with CP and SHMP. This was attributed to retaining the clusters on the trunks during the conversion year. Once the 
Table 3. Effects of training systems on components of yield of 'Merlot' grapevines on 'Freedom' rootstock in central San Joaquin Valley of California $(n=4)$.

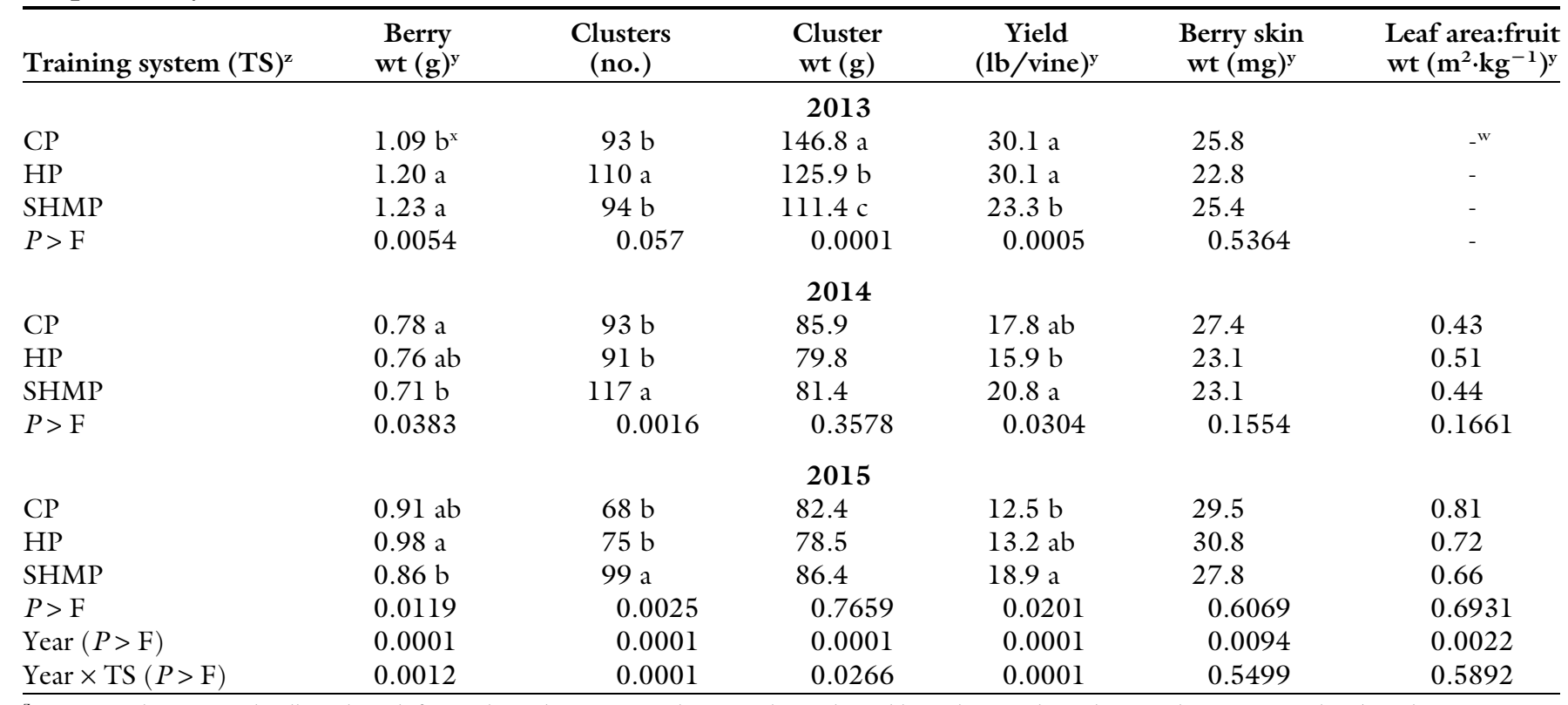

${ }^{\mathrm{z}} \mathrm{CP}=$ trained to a 38 -inch-tall trunk, with four eight-node canes trained at 44 inches and an additional two eight-node canes that were trained at 54 inches, in opposing directions; $\mathrm{HP}=$ California sprawl system with a cordon wire at 54 inches above the vineyard floor and two parallel catch wires at 66 inches above the vineyard floor and spur pruned to retain 22 spurs with two nodes each per vine; SHMP = single high-wire sprawling system cordon wire was established 66 inches above the vineyard floor and a bilateral cordon was established to generate a single high-wire system that was mechanically box-pruned at a 4.2 -inch spur height; 1 inch $=2.54 \mathrm{~cm}$.

${ }^{\mathrm{y}} \mathrm{l} \mathrm{g}=0.0353 \mathrm{oz}, \mathrm{l} \mathrm{lb}=0.4536 \mathrm{~kg}, \mathrm{l} \mathrm{mg}=3.5274 \times 10^{-5} \mathrm{oz}, 1 \mathrm{~m}^{2} \cdot \mathrm{kg}^{-1}=4.8824 \mathrm{ft}^{2} / \mathrm{lb}$.

${ }^{x}$ Columns with no letters in common indicate statistical separation at $P<0.05$ according to Tukey's honestly significant difference.

${ }^{\mathrm{w}}$ Leaf area:fruit data not collected in 2013 as canopies were being established.

training systems were established, the SHMP treatment had the greatest cluster numbers per vine by $21 \%$ and $24 \%$ in 2014 and 2015 , respectively. Cluster weight was affected by training systems only in 2013. The CP treatment had the greatest cluster weight, whereas SHMP had the lowest. Yield per vine was affected by pruning systems in all years of the study. The SHMP treatment had the lowest yield in 2013. However, the SHMP treatment increased yield by $14 \%$ and $30 \%$ in 2014 and 2015 , respectively. The number of seeds per berry was affected by training systems only in 2013.

There was a strong effect of year on most yield components, along with a number of effects attributed to training systems. Training system effects were inconclusive during the trellis conversion year in 2013 where the CP treatment was already established and the HP and SHMP treatments were in transition. The CP treatment displayed the smallest berry weight and largest clusters during this transition. However, after the completion of the canopy conversion, training system effects on yield components were more favorable for the SHMP treatment. Our results indicated that SHMP maintained the smallest berry weights once the conversion was complete. Smaller berry sizes linked to mechanical pruning were reported through a number of studies across many cultivars (Reynolds, 1998; Terry and Kurtural, 2011; Zabadal et al., 2002). This was likely attributed to a compensating response to the higher number of buds and clusters (Reynolds, 1998). In addition, water scarcity during the dormant period has been shown to reduce berry weights in subsequent years (Mendez-Costabel et al., 2014; Nelson et al., 2016). The presumably higher retention of buds in mechanized systems led to a greater number of shoots along cordons with a consequently higher number of clusters (De Toda and Sancha, 1999; Gatti et al., 2011; Geller and Kurtural, 2013), which was similar to the findings of this study. Previous research corroborated our findings that increases in yield were strongly associated with the number of clusters per vine (Nelson et al., 2016; Wessner and Kurtural, 2013). Furthermore, the lowest decrease in yield per vine in spite of the extended drought was found with the SHMP.

Skin tissue weights were unaffected by training systems in any of the post conversion years. However, skin tissue weight decreased in 2014 and 2015 due to the drought conditions, with the lowest values being found in 2014. The reductions in skin weights seen in this experiment were directly linked to the reduction in berry size and therefore were likely to be associated with the environmental and climatic stresses experienced during the experiment, as reported by Nelson et al. (2016).

Our data indicated that adjustments to current recommended leaf area-to-fruit ratio values can be considered for the hot climates as production systems move toward mechanization. Although no treatment effects were apparent, there was a significant effect of year on leaf area-to-fruit ratio. Previous research performed in locations with similar precipitation but slightly lower GDD accumulation concluded that optimum leaf area-to-fruit weight ratio for single-plane canopies, such as the HP system, was 0.8 to $1.2 \mathrm{~m}^{2} \cdot \mathrm{kg}^{-1}$, whereas values for divided canopies were lower showing optimum values between 0.5 and $0.8 \mathrm{~m}^{2} \cdot \mathrm{kg}^{-1}$ (Kliewer and Dokoozlian, 2005). In 2015, all of the training systems reached commercial maturity despite the SHMP and HP systems having lower leaf area-to-fruit ratio values than those 
considered overcropped in Kliewer and Dokoozlian (2005). Most likely the higher temperatures of our study site allowed compensation for the lower relative leaf area. In addition, such precocity in ripening in a warmer climate may allow for an extended period after harvest in which photoassimilates are greatly contributing to increase the vine's levels of reserve carbohydrates (Greven et al., 2016). This activity can essentially reduce the amount of leaf area required to ripen a given crop size (Howell, 2001). Research on 'Zinfandel' had similar conclusions showing that lower leaf area-to-fruit values in both single and divided canopies were capable of reaching commercial maturity (Nelson et al., 2016).

EFFECTS OF TRAINING SYSTEMS ON BERRY COMPOSITION. Effects on berry composition were generally inconsistent during the conversion year (Table 4). However, juice TA increased in subsequent years whereas juice $\mathrm{pH}$ was the lowest in 2014 . The SHMP treatment did not alter berry composition when compared with the traditional systems. Previous studies reported similar findings in which mechanization of winter pruning or canopy management practices had no adverse effects on primary metabolites (Brillante et al., 2018; Geller and Kurtural, 2013; Terry and Kurtural, 2011). Similarly, systems that retained more buds with mechanical box pruning were able to minimize adverse effects on berry composition (Reynolds, 1998). Therefore, our results indicated that mechanization of winter pruning did not negatively affect berry composition compared with traditional handpruned systems.

Although there were no adverse effects of training system on berry flavonoid concentration (Table 5 ) or composition seen within the current study, there was a strong effect of year on those variables (Table 6). The most apparent differences were seen within years in which there was an increase in the contribution from trihydroxylated anthocyanins (glucosides of delphinidin, petunidin, and malvidin) and a reduced contribution from dihydroxylated anthocyanins (glucosides of cyanidin and peonidin) (Table 6). Our results also indicated a shift in flavonoid composition based on the methoxylation pattern of the

Table 4. Effects of training systems on berry composition of 'Merlot' grapevine on 'Freedom' rootstock in the central San Joaquin Valley of California $(n=4)$.

\begin{tabular}{lccc}
\hline $\begin{array}{l}\text { Training } \\
\text { system }(\mathrm{TS})^{\mathrm{z}}\end{array}$ & $\begin{array}{c}\text { Total soluble } \\
\text { solids }(\%)\end{array}$ & Juice $\mathrm{pH}$ & $\begin{array}{c}\text { Titratable acidity } \\
\left(\mathrm{g} \cdot \mathrm{L}^{-\mathbf{1}}\right)^{\mathbf{y}}\end{array}$ \\
\hline & & 2013 & \\
CP & $23.1 \mathrm{a}^{\mathrm{x}}$ & $3.53 \mathrm{a}$ & $5.02 \mathrm{~b}^{\mathrm{w}}$ \\
HP & $22.1 \mathrm{~b}$ & $3.54 \mathrm{a}$ & $5.20 \mathrm{~b}$ \\
SHMP & $22.5 \mathrm{ab}$ & $3.48 \mathrm{~b}$ & $5.99 \mathrm{a}$ \\
$P>$ F & 0.0098 & 0.0045 & 0.0001
\end{tabular}

$\begin{array}{llll} & & 2014 & \\ \text { CP } & 23.3 & 3.34 & 6.23 \\ \text { HP } & 22.8 & 3.37 & 6.19 \\ \text { SHMP } & 22.4 & 3.33 & 6.39 \\ P>\text { F } & 0.1270 & 0.4069 & 0.8747 \\ & & & \\ \text { CP } & 24.3 & 3.60 & 6.66 \\ \text { HP } & 24.5 & 3.69 & 6.26 \\ \text { SHMP } & 23.7 & 3.59 & 6.61 \\ P>\text { F } & 0.1926 & 0.2342 & 0.4803 \\ & & & \\ \text { Year }(P>F) & 0.0001 & 0.0001 & 0.0001 \\ \text { Year } x \text { TS }(P>\text { F }) & 0.2681 & 0.5672 & 0.1981\end{array}$

${ }^{\mathrm{z}} \mathrm{CP}=$ trained to a 38 -inch-tall trunk, with four eight-node canes trained at 44 inches and an additional two eightnode canes that were trained at 54 inches, in opposing directions; $\mathrm{HP}=$ California sprawl system with a cordon wire at 54 inches above the vineyard floor and two parallel catch wires at 66 inches above the vineyard floor and spur pruned to retain 22 spurs with two nodes each per vine; SHMP = single high-wire sprawling system cordon wire was established 66 inches above the vineyard floor and a bilateral cordon was established to generate a single highwire system that was mechanically box-pruned at a 4.2 -inch spur height; 1 inch $=2.54 \mathrm{~cm}$.

${ }^{\mathrm{y}} 1 \mathrm{~g} \cdot \mathrm{L}^{-1}=1000 \mathrm{ppm}$.

${ }^{x}$ Columns with no letters in common indicate statistical separation at $P<0.05$ according to Tukey's honestly significant difference.

B-ring. Light exposure was not a limiting factor within this experiment, as $P A R$ values in the fruit zone were as high as $35 \%$ of the ambient. This greater level of exposure within the fruit zone likely led to an increase in the proportion of anthocyanins with two methoxyl substituents on the B-ring (malvidin-3-glucoside) and a decrease in the proportion of those with a single methoxyl group on the B-ring (delphinidin and petunidin-3glucoside). Similar results were reported in 'Syrah' (Downey et al., 2004) and 'Pinot noir' (Cortell and Kennedy, 2006). Environmental factors, such as water deficits and solar radiation, can upregulate flavonoid hydroxylases and o-methyl transferases responsible for the diversification of flavonoids (Teixeira et al., 2013); however, a differential degradation under such a hot climate leading to differences in anthocyanin profile should not be ruled out (Brillante et al., 2017). We did not follow the temporal development of anthocyanins in this experiment. However, in our previous works we deduced that anthocyanin degradation leading to anthocyanin profiles was affected by solar radiation overexposure (Martínez-Lüscher et al., 2017 b). Flavonols are normally present in much smaller concentrations than anthocyanins, but their accumulation can be greatly enhanced by the exposure to solar radiation (Matus et al., 2009). Grape berries that received more direct solar radiation had greater flavonol content than berries grown in canopy shade. Therefore, an expected response to increased incidence of solar radiation within the fruit zone would be an upregulation of genes involved in flavonol biosynthesis leading to higher flavonol content (Downey et al., 2004). A decrease in canopy development was seen within this study from 2014 to 2015. Furthermore, a reduction in light transmission through the canopy was seen in 2015. Cortell and Kennedy (2006) reported greater flavonol content as cluster exposure to light increased in a cool climate. In agreement, Yu et al. (2016) attributed an increase in flavonol content due to higher $P A R$ values as a result of pre- and post-fruit set leaf removal in a hot climate. In contrast, there was 
Table 5. Effects of training systems on berry skin anthocyanins, gallic acid, flavan-3-ols, and total flavonols of 'Merlot' grapevine on 'Freedom' rootstock in central San Joaquin Valley of California $(n=4)$.

\begin{tabular}{|c|c|c|c|c|}
\hline Training & Gallic acid & $\begin{array}{c}\text { Total } \\
\text { flavan-3-ols }\end{array}$ & $\begin{array}{c}\text { Total } \\
\text { flavonols }\end{array}$ & $\begin{array}{c}\text { Total } \\
\text { anthocyanins }\end{array}$ \\
\hline system (TS) ${ }^{\mathrm{z}}$ & \multicolumn{4}{|c|}{$\left(\mathrm{mg} \cdot \mathrm{kg}^{-1}\right)^{\mathrm{y}}$} \\
\hline & \multicolumn{4}{|c|}{2013} \\
\hline $\mathrm{CP}$ & 397.3 & 212.1 & 204.7 & $2,501.2$ \\
\hline $\mathrm{HP}$ & 495.5 & 259.6 & 218.8 & $2,861.4$ \\
\hline SHMP & 362.1 & 223.3 & 190.8 & $2,464.8$ \\
\hline \multirow[t]{2}{*}{$P>\mathrm{F}$} & 0.6806 & 0.8470 & 0.6943 & 0.6098 \\
\hline & \multicolumn{4}{|c|}{2014} \\
\hline $\mathrm{CP}$ & 201 & 109 & 671 & $1,891.9$ \\
\hline $\mathrm{HP}$ & 672 & 112 & 679 & $2,132.4$ \\
\hline SHMP & 583 & 96 & 691 & $2,036.1$ \\
\hline \multirow[t]{2}{*}{$P>\mathrm{F}$} & 0.2924 & 0.5226 & 0.8972 & 0.4511 \\
\hline & \multicolumn{4}{|c|}{2015} \\
\hline $\mathrm{CP}$ & 1,144 & 34.9 & 115.5 & $2,238.6$ \\
\hline $\mathrm{HP}$ & 977 & 33.4 & 123.1 & $2,461.7$ \\
\hline SHMP & 1,052 & 32.1 & 146.0 & $2,308.6$ \\
\hline$P>F$ & 0.2120 & 0.6839 & 0.8161 & 0.8125 \\
\hline Year $(P>\mathrm{F})$ & 0.0148 & 0.0001 & 0.0001 & 0.0558 \\
\hline Year $\times \mathrm{TS}(P>\mathrm{F})$ & 0.1337 & 0.6404 & 0.9883 & 0.7379 \\
\hline
\end{tabular}

${ }^{\mathrm{z}} \mathrm{CP}=$ trained to a 38 -inch-tall trunk, with four eight-node canes trained at 44 inches and an additional two eight node canes that were trained at 54 inches, in opposing directions; $\mathrm{HP}=$ California sprawl system with a cordon wire at 54 inches above the vineyard floor and two parallel catch wires at 66 inches above the vineyard floor and spur pruned to retain 22 spurs with two nodes each per vine; SHMP = single high-wire sprawling system cordon wire was established 66 inches above the vineyard floor and a bilateral cordon was established to generate a single highwire system that was mechanically box-pruned at a 4.2 -inch spur height; 1 inch $=2.54 \mathrm{~cm}$.

${ }^{\mathrm{y}} \mathrm{l} \mathrm{mg} \cdot \mathrm{kg}^{-1}=1 \mathrm{ppm}$

a strong effect of year on total flavonols within this experiment in which their content decreased in 2015 , although an increase would normally be expected in response to greater solar radiation exposure in that year. However, exposure levels within this experiment displayed fruit zone $P A R$ values $\approx 35 \%$ during fruit maturation, indicating the role high temperatures may have on the inhibition or degradation of flavonol compounds. Inhibition of flavonols in red wine grapes has been reported as a consequence of exposure to higher temperatures (Nelson et al., 2016; Spayd et al., 2002). Previous research has supported the idea of improvements in the light microclimate of grapevine canopies as a method of improving flavonol content (Downey et al., 2004; Yu et al., 2016). Our results indicated that reductions in flavonols can be observed in response to increasing exposure to solar radiation, which may possibly be mediated by elevated berry temperature (Martínez-Lüscher et al., 2017b).

A reduction of total flavan-3-ol monomers within skin tissues was also seen in 2015 within this experiment. Flavan-3-ols contents within the skin are linked to fruit ripening, decreasing sharply after veraison (Cortell and Kennedy, 2006). The greater flavan3 -ol values seen in 2014 can be attributed to the fruit being harvested well before commercial maturity was reached. Solar radiation exposure was also shown to affect flavan-3-ol content. Exposed fruit has been shown to have greater flavan-3-ol content than shaded in cooler climates (Cortell and Kennedy, 2006). Similar to the findings on flavonols within this experiment, increased exposure due to mitigation of canopy development led to a decrease in total flavan-3ols. These findings are consistent with results seen by Castellarin et al. (2007), who reported that water deficits significantly increased anthocyanins but had minimal effects on flavonols and skin tannins.

Cost COMPARISONs. The labor operation costs for the three training systems (Table 7) were analyzed as reported by Kurtural et al. (2012). The CP treatment had the highest labor operation cost per acre during the course of the experiment, although it was already established. The training system conversion costs were similar for HP and SHMP. Verdagaal et al. (2016) reported $27 \%$ of the labor operation cost in an acre of a 'Cabernet Sauvignon' vineyard was attributed to dormant pruning. Our results indicated that this was slightly higher for CP but similar in HP treatment. Furthermore, following the conversion year, the SHMP reduced the pruning cost per acre by $\approx 90 \%$ compared with both $\mathrm{CP}$ and HP. In the following year (2015), even though the skilled labor rate increased for SHMP, the labor operations cost savings were still evident. Furthermore, at the end of the study, even though the price received per ton of 'Merlot' grapevine at the farm gate declined (CDFA, 2014, 2015), the SHMP was the most profitable, although the initial year of the study was spent on converting the vineyard to this system.

\section{Conclusion}

Conversion of traditional systems over to a single high-wire mechanically box-pruned system can be effectively managed in the hot climate while maintaining similar berry composition of 'Merlot' grapevine. The effect of year seen in subsequent years throughout the study provided evidence that the buffering capacity the SHMP treatment has in response to untoward climate conditions. This was indicated through the minimal reductions in yield in the SHMP system in subsequent years compared with the $\mathrm{HP}$ and CP treatments. There were a number of compensating mechanisms that grapevines have in response to a higher number of retained nodes. The SHMP system displayed an earlier development of leaf area, indicating faster canopy fill. Earlier development of canopy leaf area when coupled with sufficient reproductive compensating responses allowed for increased yields while reaching commercial maturity without a decline in anthocyanin content such as that found within the current study. The SHMP is recommended for growers within the hot climate of the central SJV to increase the sustainability of production while not sacrificing an adequate berry composition. 


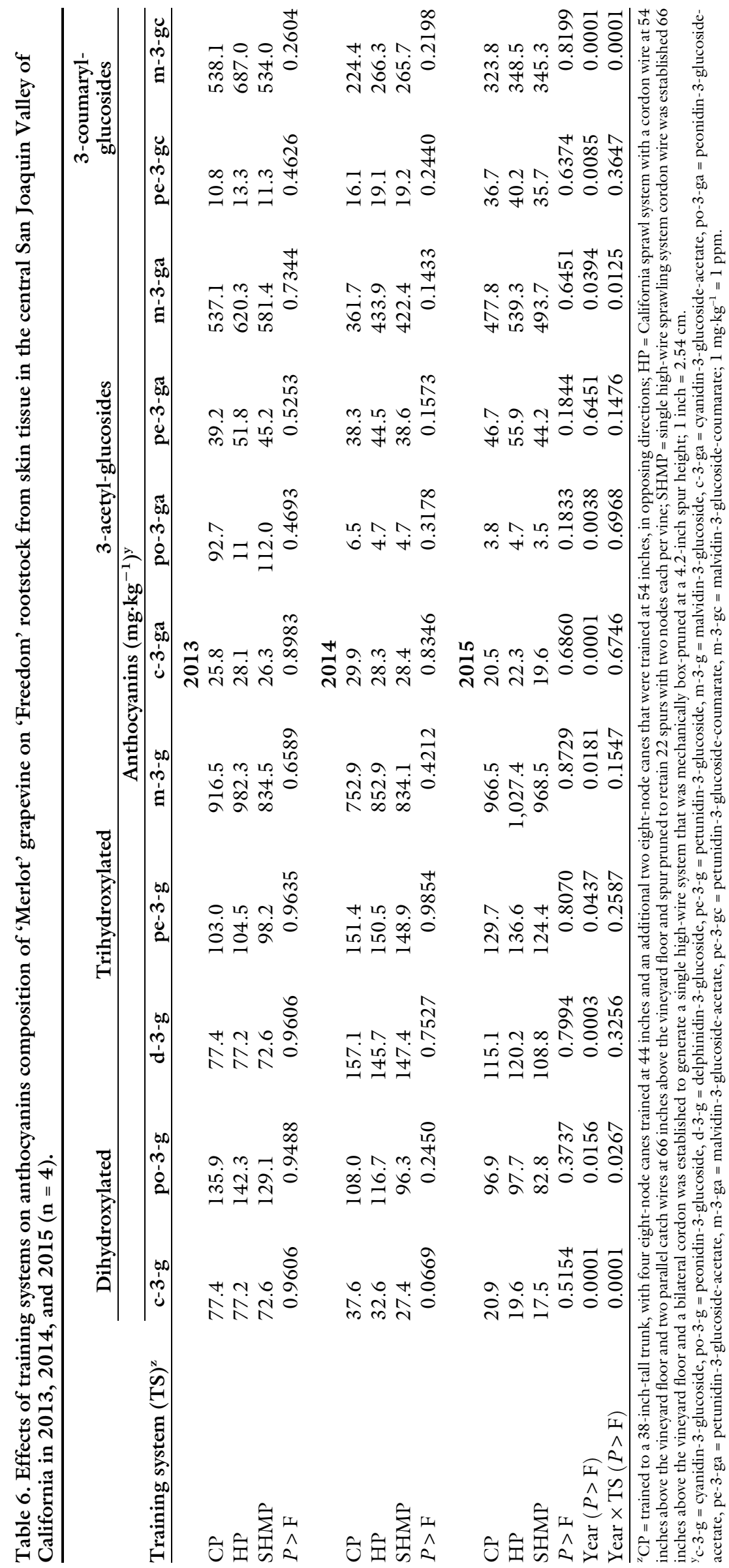


Table 7. Labor operations costs, gross revenue, and net income per acre of 'Merlot' grapevine on 'Freedom' rootstock during transitioning to mechanical pruning in central San Joaquin Valley of California.

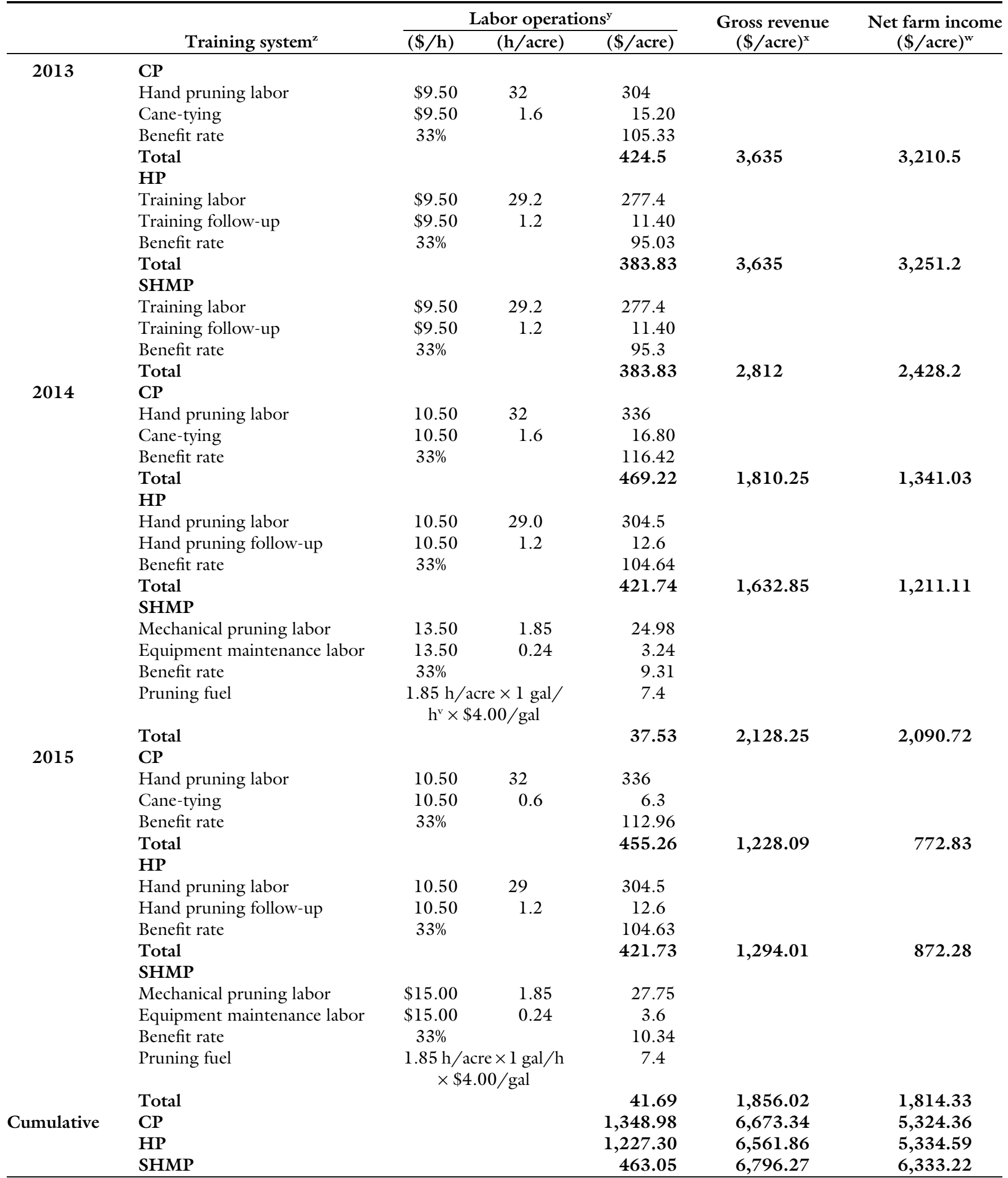

${ }^{\mathrm{z}} \mathrm{CP}=$ trained to a 38 -inch-tall trunk, with four, 8 -node canes trained at 44 inches and an additional two, 8 -node canes that were trained at 54 inches, in opposing directions, $\mathrm{HP}$ $=$ California Sprawl system with a cordon wire at 54 inches above the vineyard floor and two parallel catch wires at 66 inches above the vineyard floor and spur pruned to retain 22 spurs with two nodes each per vine, SHMP = single high-wire sprawling system cordon wire was established 66 inches above the vineyard floor and a bilateral cordon was established to generate a single high-wire system that was mechanically box-pruned at a 4.2 inch spur height, and mechanical pruner's speed was $0.5 \mathrm{mph}\left(0.80 \mathrm{~km} \cdot \mathrm{h}^{-1}\right) ; \mathrm{l}$ inch $=$ $2.54 \mathrm{~cm}$.

${ }^{\mathrm{y}} 1 \mathrm{~h} / \mathrm{acre}=2.471 \mathrm{l} \mathrm{h} \cdot \mathrm{ha}^{-1}, \$ 1 / \mathrm{acre}=\$ 2.471 \mathrm{l} / \mathrm{ha}, \mathrm{l} \mathrm{gal}=3.7854 \mathrm{~L}, \$ 1 / \mathrm{gal}=\$ 0.2642 / \mathrm{L}$

'Merlot' price/ton is based on average price for Crush District 13 in 2013-15 according to the California Department of Food and Agriculture (2013, 2014, 2015).

"Net farm income calculated gross farm receipts - labor operations costs. 


\section{Literature cited}

Amerine, M.A. and A.T. Winkler. 1944. Composition and quality of must and wines of California grapes. Hilgardia 15:493-673.

Bergqvist, J., N. Dokoozlian, and N. Ebisuda. 2001. Sunlight exposure and temperature effects on berry growth and composition of Cabernet Sauvignon and Grenache in the central San Joaquin Valley of California. Amer. J. Enol. Viticult. 52:1-7.

Brillante, L., J. Martínez-Lüscher, and S. K. Kurtural. 2018. Applied water and mechanical canopy management affect berry and wine phenolic and aroma composition of grapevine (Vitis vinifera L., cv. Syrah) in central California. Scientia Hort. 227:261-271.

Brillante, L., J. Martínez-Lüscher, R. Yu, C.M. Plank, L. Sanchez, T. Bates, C. Brenneman, A. Oberholster, and S.K. Kurtural. 2017. Assessing spatial variability of grape skin flavonoids at the vineyard scale based on plant water status mapping. J. Agr. Food Chem. 65:5255-5266.

California Department of Food and Agriculture. 2013. Grape crush report Final 2013. 1 Apr. 2014. <http://www. nass.usda.gov/Statistics_by_State/ California $>$.

California Department of Food and Agriculture. 2014. Grape crush report Final 2014. 1 Apr. 2015. <http://www. nass.usda.gov/Statistics_by_State/ California>.

California Department of Food and Agriculture. 2015. Grape crush report Final 2015. 1 Apr. 2016. <http://www. nass.usda.gov/Statistics_by_State/ California>.

Castellarin, S.D., A. Pfeiffer, P. Sivilotti, M. Degan, E. Peterlunger, and G. Di Gaspero. 2007. Transcriptional regulation of anthocyanin biosynthesis in ripening fruits of grapevine under seasonal water deficit. Plant Cell Environ. 30:13811399.

Cook, M.G., Y. Zhang, C.J. Nelson, G. Gambetta, J. Kennedy, and S.K. Kurtural. 2015. Anthocyanin composition of Merlot is ameliorated by light microclimate and irrigation in central California. Amer. J. Enol. Viticult. 66:266-278.

Coombe, B.C. 1995. Adoption of a system for identifying grapevine growth stages. Austral. J. Grape Wine Res. 1:104110.

Cortell, J.M. and J.A. Kennedy. 2006. Effect of shading on accumulation of flavonoid compounds in (Vitis vinifera L.) Pinot Noir fruit and extraction in a model system. J. Agr. Food Chem. 54:8510 8520 .

De Toda, F.M. and J.C. Sancha. 1999. Long-term effects of simulated mechanical pruning on Grenache vines under drought conditions. Amer. J. Enol. Viticult. 50:87-90.

Downey, M.O., J.S. Harvey, and S.P. Robinson. 2004. The effect of bunch shading on berry development and flavonoid accumulation in Shiraz grapes. Austral. J. Grape Wine Res. 10:55-73.

Gatti, M., S. Civardi, F. Bernizzoni, and S. Poni. 2011. Long-term effects of mechanical winter pruning on growth, yield, and grape composition of Barbera grapevines. Amer. J. Enol. Viticult. 62:199-206.

Geller, J.P. and S.K. Kurtural. 2013. Mechanical canopy and crop-load management of Pinot Gris in a warm climate. Amer. J. Enol. Viticult. 64:65-73.

Greven, M.M., S.M. Neal, D.S. Tustin, S. Boldingh, J. Bennett, and M.C. Vasconcelos. 2016. Effect of postharvest defoliation on carbon and nitrogen resources of high-yielding Sauvignon Blanc grapevines. Amer. J. Enol. Viticult. 67:315-326.

Howell, G. 2001. Sustainable grape productivity and the growth-yield relationship: A review. Amer. J. Enol. Viticult. 56:105-112.

Keller, M., R. Smythman, and L.J. Mills. 2008. Interactive effects of deficit irrigation and crop load of Cabernet Sauvignon grapevines in an arid climate. Amer. J. Enol. Viticult. 59:221-234.

Kliewer, W.M. and N.K. Dokoozlian. 2005. Leaf area/crop weight ratios of grapevines: Influence on fruit composition and wine quality. Amer. J. Enol. Viticult. 56:170-181.

Kurtural, S.K., G. Dervishian, and R.L. Wample. 2012. Mechanical canopy management reduces labor costs and maintains fruit composition in 'Cabernet Sauvignon' grape production. HortTechnology 22:510-516.

Kurtural, S.K., L.F. Wessner, and G. Dervishian. 2013. Vegetative compensation response of a procumbent grapevine (Vitis vinifera cv. Syrah) cultivar under mechanical canopy management. HortScience 48:576-583.

Martínez-Lüscher, J., L. Brillante, C. Nelson, A. Al-Kereamy, G. Zhuang, and S.K. Kurtural. 2017a. Precipitation before bud break and irrigation affect the response of grapevine 'Zinfandel' yields and berry skin phenolic composition to training systems. Scientia Hort. 222:153161.
Martínez-Lüscher, J., C. Chen, L. Brillante, and S.K. Kurtural. 2017b. Partial solar radiation exclusion with color shade nets reduces the degradation of organic acids and flavonoids of grape berry (Vitis vinifera L.). J. Agr. Food Chem. 65:10693-10702.

Matus, J.T., R. Loyola, A. Vega, A. PenaNeira, E. Bordeu, P. Arce-Johnson, and J.A. Alcalde. 2009. Post-veraison sunlight exposure induces MYB-mediated transcriptional regulation of anthocyanin and flavonol synthesis in berry skins of Vitis vinifera. J. Expt. Bot. 60:853867.

Mendez-Costabel, M., K.L. Wilkinson, S. Bastian, C. Jordans, C. Ford, and N. Dokoozlian. 2014. Effect of winter rainfall on yield components and fruit green aromas of Vitis vinifera L. cv. Merlot in California. Austral. J. Grape Wine Res. 20:100-110.

Nelson, C.C., J.A. Kennedy, Y. Zhang, and S.K. Kurtural. 2016. Applied water and rootstock affect productivity and anthocyanin composition of Zinfandel in central California. Amer. J. Enol. Viticult. 67:18-28.

Reynolds, A. 1998. Response of Okanagan Riesling vines to training system and simulated mechanical pruning. Amer. J. Enol. Viticult. 39:205-212.

Smart, R. and M. Robinson. 1991. Sunlight into wine. Winetitles, Adelaide, Australia.

Spayd, S.E., J.M. Tarara, D.L. Mee, and J. C. Ferguson. 2002. Separation of sunlight and temperature effects on the composition of cv. Merlot berries. Amer. J. Enol. Viticult. 53:171-182.

Teixeira, A., J. Eiras-Dias, S.D. Castellarin, and H. Geros. 2013. Berry phenolics of grapevine under challenging environments. Intl. J. Mol. Sci. 14:1871118739.

Terry, D.B. and S.K. Kurtural. 2011. Achieving vine balance of Syrah with mechanical canopy management and regulated deficit irrigation. Amer. J. Enol. Viticult. 62:426-437.

University of California. 2014. Grape pest management guide. 15 Jan. 2019. <http://www.ipm.ucdavis.edu/PMG/ selectnewpest.grapes.html>.

U.S. Department of Agriculture. 2006. Soil survey staff official soil series descriptions. 1 Apr. 2013. <https:// soilseries.sc.egov.usda.gov/OSD_Docs/ C/COMETA.html>.

Verdagaal, P., A. Daniel, and J.M. Sumner. 2016. To establish a vineyard and produce wine grapes: Cabernet Sauvignon variety San Joaquin Valley 
North-San Joaquin and Sacramento counties Crush District 11. Univ. California Coop. Ext. Serv. Bul. GR-VNI6.

Webb, L.B., I. Watterson, J. Bhend, P.H. Whetton, and E. Barlow. 2013. Global climate analogues for winegrowing regions in future periods: Projections of temperature and precipitation. Austral. J. Grape Wine Res. 19:331-341.
Wessner, L.F. and S.K. Kurtural. 2013. Pruning systems and canopy management practice interact on the yield and fruit composition of Syrah. Amer. J. Enol Viticult. 64:134-138.

Yu, R., M. Cook, R. Yacco, A. Watrelot, G. Gambetta, J.A. Kennedy, and S.K. Kurtural. 2016. Effects of leaf removal and applied water on flavonoid accumulation in grapevine (Vitis vinifera L. cv. Merlot) berry in a hot climate. J. Agr. Food Chem. 64:8118-8127.

Zabadal, T.J., G.R. Vanee, T.W. Dittmer, and R.L. Ledebuhr. 2002. Evaluation of strategies for pruning and crop control of Concord grapevines in southwest Michigan. Amer. J. Enol. Viticult. 53:204-209. 